\title{
Humberto Maturana's view on the theory of evolution. From autopoiesis to natural drift metaphor
}

\author{
Jacek S. Podgórski \\ Department of Philosophy of Science, Institute of Philosophy, \\ Nicolaus Copernicus University, Fosa Staromiejska 1a, 87-100 Toruń, Poland \\ e-mail: jacpod@doktorant.umk.pl
}

\begin{abstract}
Today in the scientific circle Humberto Romensin Maturana is considered the creator of the so-called Santiago School of Biology (also known as Biology of Cognition). Biology of Cognition is a research programme seeking an explanation of the phenomenon of cognitive functions of living organisms through the concepts of self-organization (from dynamical systems theory) and structural coupling (from cybernetics).

Maturana's novel view is based upon research conducted with such prominent scientists like Warren McCulloch, Francisco J. Varela or Heinz von Foerseter. After many years of study of complex organic systems the research resulted in formulation of the following theories: autopoiesis of living systems (with F. J. Varela) and the evolutionary metaphor of natural drift (with J. Mpodozis). Theory of autopoiesis (self-production) shows how organic cells organize themselves in producing inner organic self components needed for maintaining homeostatis, natural barriers and remaining cognitive at the molecular level. By contrast, the metaphor of natural drift can be understood as the history of diversification and adaptation of species in relation to many structural levels of the environment.

The following article constitutes a brief introduction to a critical way of thinking of the said Chilean theoretical biologist and philosopher, established during his long-lasting research. The paper will outline the basic concepts and theoretical implications relevant to modern biological sciences, with particular emphasis on the classical theory of evolution.
\end{abstract}

Keywords: Santiago School of Biology, self-organization, principles of biological autonomy, structural coupling, enactive approach.

\section{Introduction}

In this paper I will be primarily discussing a certain way of thinking about biology and the use of metaphorical language rather than the scientific jargon. I will discuss an unprecedented way in which the natural world can be seen by a scientist and a philosopher.

The purpose of this article is to present key concepts considering views of Humberto R. Maturana and his colleagues, bring closer the literature, outline the practical applications of their research thus presenting a different perspective on biology and the phenomenon of evolution, and ultimately determine whether it is an interesting view its concepts and methodology. Specifically, I would like to discover misapplication of these concepts and take a glance at a different way of thinking about biology.

This paper won't provide a full description of autopoiesis theory and natural drift metaphor, present all of their implications for human evolution, and finally convince the reader that the ideas of the Santiago School of Biology pave the only right way of thinking about biology of complex organisms.

The article is divided into six sections. The first section provides a brief historical overview, profiles of the 
discussed scientists as well as the thematic literature. This section will contain a bibliographic guide for philosophers and biologists interested in the sciences of complexity, the theory of evolution and neurophysiology. The second section defines the term of autopoiesis as a constituent of the natural drift metaphor. The third section introduces Varela's scientific view concerning the autonomy of biological systems. The fourth section discusses the concept of adaptation in the light of philosophical reflections of Maturana and his associates. The fifth section presents the metaphor of natural drift as a mature reflection on the concepts of adaptation and self-organization of living organisms in the context of evolutionary theory.

\section{Main Part}

This paper focuses not only on the scientific inquiries of Humberto Maturana, but also on creative thoughts of Francisco Varela and Jorge Mpodozis. All of the above-mentioned gentlemen are theoretical biologists by training, as well as specialists in the related fields (neurophysiology, immunology, etc.).

Humberto Maturana was born in 1928 in Chile. He first studied medicine there, later he began studying biology at Harvard University in London (where he became known as an outstanding student of a philosopher and biologist - Ernst Mayr), and graduated in 1958. Until 1960 he worked as a physiologist (Lettvin et al. 1959) at MIT at the laboratory of the Institute of Radio Engineering along with a cyberneticist Warren McCulloch. It was there that he made the interesting findings on vertebrate visual system (Boycott et al. 1965; Maturana et al. 1968). Since then he has lived in Chile. His specialty in biology is cognition. He is also known as a philosopher (Maturana 1990; Mingers 1990).

Francisco Varela was also born in Chile, in 1954. He studied biology and obtained his Ph.D. degree at the age of 23 in Harvard, like Maturana. He fled from Chile in 1973 for political reasons and since 1986 lived in Paris, where he tragically died in 2001. Varela was a student of Maturana, and together they developed the ideas of autopoiesis, structural coupling and natural drift. He worked on many scientific projects including immunology (developing idiotypic network theory of Niels K. Jerne (Varela 1979, p. 238; Varela \& Coutinho 1991; Detours et al. 1994), neuroscience (McMullin \& Varela 1997; Varela 1997; Boden 2000), psychotherapy (Varela 1989), etc.

Mpodozis replaced Varela after his tragic death. As an assistant he sought to develop new projects of his still extremely fertile teacher and mentor. His most famous article is The origin of species by means of natural drift written together with Maturana (2000) in which he fully develops the earlier presented idea of evolution seen as a natural drift (Maturana \& Varela 1987, p. 93), or a historical float of structural couplings between organisms and the environment at the molecular level.

When speaking about the concept of natural drift I refer to the metaphor relating to the reflection on the three basic concepts: a) autopoiesis, b) autonomy, c) adaptation. In 1975, Maturana released his first paper regarding the topic of Biology of Cognition (Maturana 1975), although he did not use the term autopoiesis in it. In 1979, a young student of Maturana, Francisco Varela, tried to formalize their thoughts by publishing the book titled Principles of Biological Autonomy, and so spread the ideas wider (Varela 1979). In 1980, the third well-known book was released, Autopoiesis and Cognition: The Realization of the living, published by both researchers. This book shows fully developed philosophical thoughts on the complexity of biological systems; their relations to the environment; and ways of their interaction and organization (Varela \& Maturana 1980).

The mysterious term of natural drift was first introduced in 1987 by both Maturana and Varela, in the book entitled The Tree of Knowledge: The Biological Roots of Human Understanding (1987). After many years of research Maturana with his new assistant, Jorge Mpodozis, decided to further extend the idea of natural drift. In 1999 they presented the paper: The origin of species by means of natural drift (Maturana \& Mpodozis 2000) as an analogical and competitive way of thinking for neo-Darwinism.

\section{What is autopoiesis?}

What exactly does the word autopoiesis mentioned at the beginning as a natural component of the theory of natural drift stand for? Autopoiesis in translation from Greek

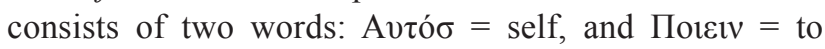
produce. Autopoiesis means, as the translation above already implied, the continuous "self-producing" of a system. It means, an organism consisting of many components continuously recreates itself through its components. Every component creates (or takes part in a creation process of) other components, which themselves create again other components and so on. In a living organism, this creation-process is closed, that means all components create each other in a circular organization without help from the "outside". As we can see the description must be given in mechanistic terms. Maturana and Varela state that "all living systems operate in a mechanistic way, so the definition must be purely mechanistic", and so: "living systems are machines" (Varela \& Maturana 1980, p. 77).

The word Autopoiesis appears in literature in two different ways: a) as a set of interconnected ideas aimed at providing the definition of life and explanations for biological phenomena (theory of autopoiesis), b) when ap- 
proaching this word more fundamentally, we speak about defining properties of living organisms.

The inspiration for this concept was provided from many fields: philosophers (for example: the Polish thinker Bronisław Trentowski or the French vitalist Herni Bergson), psychologists (Piaget, among many others), phenomenology (strong emphasis on the work of Merleau-Ponti), and finally, cyberneticists (Glasersfeld and Foerster) (Zelezny 1997).

While discussing autopoiesis we must first consider the two fundamental axioms. First, the axiom of structural determinism which assumes that life is not magic, but is defined through system dynamics depending only on structural composition - based on operational rights, specifically the laws of physics, with particular emphasis on the 1st and the 2nd law of thermodynamics (Mingers 1995; Luisi 2006). The second axiom is manifested in the famous quotation "All that is said is said by an observer". This axiom implies that a Scientist-Observer needs to take on a specific research attitude in relation to experiment and obtained knowledge. In the opinion of Santiago biologists the method of self-reflection is the only way to reach an objective image of reality and thus achieve the desired results (Varela \& Maturana 1980, p. 8).

What, then, is life as a quintessential property of every living being? Life means having the ability of - and here we can open list: growth, reproduction, adaptation, metabolism, autonomy, genetic heredity, self-organization, entropy reduction, self-modification (Luisi et al. 1996; Mingers 1989). This list shows that all these features are quite confusing and fuzzy. According to researchers from Santiago, we must first ask and answer the following question: What exactly is this living organism? To solve this doubt, it is necessary to operationalize the concept of "life" (Fleischaker 1988). Therefore, the question must be reformulated: What is the invariable feature of all living systems; referring to them at the present moment?

Reply: The fact that any biological system is always constituted (in the physical sense) in such a way as to remain separate from their physical environment. If this process is interrupted - that system dies. Autopoiesis is a system, and therefore alive.

In summary, every autopoietic system consists of: i) organization (set of all relations between components that build a unity of a particular class); ii) structure (set of all relations in an actual system that build this system). All components take part in continuous producing themselves (circular organization), and one or more components define a border of the system, so that the system is a single unity (structure) (Fleischaker 1988, p. 132; Varela 1979, p. 15; Varela \& Maturana 1980, p. 88).

How to prove the rightness of the Santiago theory of self-organization? According to Maturana and others (Varela 1979, p. 19; Varela \& Maturana 1980, p. 90) - the simplest way to verify the correctness of autopoietic theory is to focus on the simple model. Physical embodiment of Maturana and Varela definition of a living system can be seen in a descriptive model of eukaryotic cell (Fleischaker 1988, p. 141; Luisi \& Varela 1989; Luisi 2002). The cell creates continuously its own components (nucleus, mitochondria, ribosome, membrane, etc.). The membrane separates the inner parts of the cell from the outside, covers all of the cell. All components have electrochemical properties, follow general physical laws and interact with each other. The membrane is built from inside the cell and does determine the "end" of the cell in any direction by itself and is created and continuously reproduced by the other components in the cell.

Today the theory of autopoiesis is regarded as the cornerstone of Biology of Cognition. Application of the theoretical assumptions of Maturana and Varela (autopoietic methodology) leads to multi-disciplinary research programme, that can be clarified by means of several key concepts (closer or further related to the concept of autopoiesis):

- evolution seen as progress - it is not necessary, because every living organism is considered as a autopoietic system which is based on its structurally conditioned skills and abilities (Lewontin 1983a; Maturana \& Mpodozis 2000; Mingers 1995),

- natural selection is a consequence of evolution, not its cause (Maturana \& Varela 1987; Kauffman 1993; Varela 1979),

- life cannot exist without physical limitations - for example: a cell cannot exist without its boundaries (Fleischaker 1988; Zeleny 1997),

- genotype does not determine phenotype (Lewontin 1983a; Maturana \& Mpodozis 2000),

- an organism cannot exist without the environment, and the environment without a body (Boden 2000; Luisi 2002; Mingers J., 1990; Zeleny 1977),

- the mind is not in the head, the brain is not a computer - for example: people can extend their cognitive abilities onto artifacts (Maturana 1985),

- cognition equals life - living complex organisms cannot exist without cognitive abilities (Luisi et al. 1996; Varela \& Maturana 1980),

- the nervous system is not processing information (Boycott et al. 1965; Lettvin 1959; Varela \& Maturana 1980),

- the internal representations (notion from philosophy of mind) are a category mistake (Maturana 1990),

- communication is not a transfer of information (Kincaid 1987; Krippendorff 1987; Luhmann 1986),

- artificial life is possible from a logical point of view if, and when, it is embodied and metabolized (Varela \& Bourgine 1991). 


\section{Francisco Varela's definition of biological autonomy}

The concept of biological autonomy in philosophical view of Francisco Varela is extended to organisms with a greater degree of complexity, with isolated sub-modules shaped on the principle of recursive generation of network changes. An example of autonomous beings are all these organisms that are built from autopoietic units (for example: organic cells); that have minimal signs of the nervous or immune system (Varela 1979, p. 211; Varela \& Maturana 1980, p. 15; Varela 1997).

The theory of autopoiesis places the notion of autonomy at the center of the biological understanding of all living beings (Varela 1979, p. 41; Varela \& Maturana 1980, p. 85). Autonomy means self-law, being in charge. In general, this is understood either as the capacity to: a) act according to self-determined principles, b) or as the duty of recognizing and respecting that aptitude about someone. In an ontological usage it may also mean that a given level or realm is relatively independent with respect to others because it is ruled by its own norms. According to Maturana and Varela's theory of autopoiesis, autonomous capacities stem from self-production and they constitute a living entity (Fleischaker 1988; Kauffman 1993; Varela 1979, p. 55). In short: autopoiesis is the mechanism that imparts autonomy to the living.

\section{Criteria of adaptation}

Adaptation is a one of a kind ability that characterizes all living organisms; it is one of the highest forms of behavior. In the view of Maturana and others (Fleischaker 1988, p. 135) it is equated with the ability to keep being alive - being autopoietic, maintaining open structure: receive "impulses" from the environment and react adequately, and finally preserve the unique organization by organizational closure (keep boundaries, and so the identity) (Varela 1979, p. 8; Varela \& Maturana 1980). The process of evolution is a valid expression of ontogeny, of the unique characteristics of certain species acquired by phylogeny (ancestral development). In literature, researchers sometimes refer to adaptation as a form of mutualism.

In the opinion of Maturana and others (Varela 1979, p. 24; Varela \& Maturana 1980), if we look at any autopoietic system through the categories of an organizational homeostasis, we may be able to see many adaptive criteria. Living system is organized as a network of processes of assembly, transformation, and destruction of components. In this evolutionary, long-established way of interaction every living organism regenerates and optimizes its states (inner relations) for maintaining its identity (unique ontogeny). The second interesting feature is the fact, that living systems are constituted of / constitute a specific topological space - are created by / create environment.

Summarizing the discussion on the definition of life (or being alive) - what are the criteria for showing that the system is alive or artificial, thus adaptive or passive? There are six gradual criteria formalized by Varela, using the George Spencer Brown's calculus of indications (Varela 1979). If you answer "yes" to all of the following questions you will deal with an autopoietic adaptive system: a) Has the unity identifiable boundaries? b) Does the unity consist of components and do these components constitute the unity? c) Is the unity a mechanistic system, that is, do the components have relations to and do they interact with each other? d) Do the components that build the boundaries of the unity do that by themselves, that is, don't you as the observer determine the boundaries? e) Are the components that build the boundaries produced by the other components and do they take part in the whole producing process? f) Are all other components also produced by each other and take part in the whole producing process? (Varela 1979, p. 55).

As we can see, being adaptive is to maintain closed operational organization (type of class), with dynamically open structure that can preserve its identity in relation to changing environment, etc. (Varela 1979, p. 24).

In the context of defining criteria of adaptation in living organisms, the phenomena concerned with social behavior are also very important (Dell 1985; Foerster 1973; Maturana 1995). According to Maturana and others, social structures - are the result of biological organization, biological forms based on the structural coupling between systems and their surroundings: engaging in interactions, coordination and developing structural suitability (or conservative adequate behavioral schemes).

\section{The natural drift metaphor}

According to Maturana and others, in order to characterize all the phenomena of the natural world there is a need of a good definition of life, autonomy, adaptation. The metaphor of the natural drift (Maturana \& Varela 1987; Maturana \& Mpodozis 2000; Camus 2000) brought together all the ideas of biologists from Santiago and is seeking a broader - holistic - way to characterize the concept of evolution, while still retaining the two axioms previously posed (axiom of structural determinism; and self-referring observer). The proposition of Maturana and others (2000; Lewontin 1991) in many points agrees with the concept of life characterized by Lynn Margulis and others (Luisi 2006).

What is natural drift and how does it characterize evolution? Since the dynamics of the environment may be erratic, the result in terms of evolution is a natural drift, 
determined primarily by the inner coherence and autonomy of the living organism. In this sense, Maturana and Varela's view (Maturana \& Varela 1980, 1986) is close to Gantis's $(1975,2003)$ theory of chemotons or Prigogine's theory of changes in dissipative structures (Kauffman 1993). Evolution does not pursue any particular aim - it simply drifts. The path it chooses is not, however, completely random, but is one of many that are in harmony with the inner structure of the autopoietic unit. These coupled interactions, accumulated over time, give a particular historical perspective to the autopoietic system. It becomes a historical product, the result of a long series of coupled interactions.

Evolution is not progress, it is simply drift. Natural drift is a dynamical mechanism (at structural level) that gave rise to the diversity of living systems that we find today, as well as to the biosphere as a coherent system of interrelated autonomous living systems. Natural drift refers to the history of living systems on earth, that is the history of the arising, conservation, and diversification of lineages through reproduction, and not of populations (Maturana \& Varela 1987; Lewontin 1991).

Maturana and others are saying that biological reproduction is a systemic process of conservation of a particular ontogenic-phenotype / ontogenic-niche relation, and not a genetic process of conservation of some genetic constitution (particular genotype) (Rozzi et al. 1988).

Although nothing can happen in the life history of a living system that is not permitted by its total genotype, whatever happens in it arises in an epigenetic manner, and it is not possible to properly claim that any feature that arises in the life history of an organism is genetically determined (Maturana \& Varela 1987, p. 99; Maturana \& Mpodozis 2000). At many points Maturana and others argue that behavior guides the course of the history of living systems, not genetics. Santiago Biologists are basically saying that it is not the genes that reflect evolutionary changes, but the gene-environment interactions.

Lewontin (1991, p. 101) mentions that the atmosphere that we all breathe was not on earth before living organisms and adds:

"(...) there is no "environment" in some independent and abstract sense. Just as there is no organism without an environment, there is no environment without an organism. Organisms do not experience environments. They create them. They construct their own environments out of the bits and pieces of the physical and biological world, and they do so by their own activities."

What are the essential differences between the theory of Maturana and the followers of neo-Darwinism? In the case of natural drift an evolutional unit is a self-organizing network set-up (autopoietic system). Structural coupling is a mechanism of selection, and refers to the recognition that a system's structural relationship with its environment will determine its responses to disturbances or triggers. So it occurs on both sides (of the organism and the environment). Organism and environment mutually determine each other through a set of historical networks, so that they cannot exist without each other (Lewontin 1983b; Varela \& Maturana 1987, p. 86).

By contrast, the neo-Darwinian view at evolutional unit consists of a whole population of genes whose form is focused on heredity, mutations, etc. The selection is understood by the concept of adaptation (adaptation of the organism to the environment), there are good and unique structures that are adapting to solve problems. The environment is supreme, independent of the organisms, is the "selector" for organisms, where the organism through random genes adopts to the environment in a successful or unsuccessful way (Lewontin 1983a; Varela 1979, p. 30; Varela \& Maturana 1980, p. 102).

The interaction between organisms and their environment is a part of a more general scenario of ecology (Maturana \& Varela 1987, p. 112). It has been in fact stated that living organisms make and continuously change the environment in which they live, and vice versa, so that every act of consumption is also an act of production; also, that we must forget the idea that there is a constant and fixed world - as we are constantly changing it and cannot live without changing it. (Lewontin 1991). From that stems the difficulty of finding a healthy equilibrium that preserves as much as possible the identity of the living (Oyama 2000, p. 142).

\section{Conclusion}

In conclusion - organisms are historical systems, constructed in a circular way (closed organizationally, structurally open). By contrast, evolution is a complicated network of interactions at the level of ontogenetic plasticity of the species, etc. Thus, I put forward the question: Is autopoiesis with the metaphor of the natural drift a scientific theory? Not entirely, it should be taken as a way of using specific language with particular terms, rather than as a scientific theory in the strict sense and not even like in the classical philosophy of biology (Camus 2000).

What is its value? It is certainly a very complicated theory, logically coherent, leaning on complicated language. This theory is not false, or verifiable. Transferring it to another scientific discipline, it appears to be more or less adequate in a particular field of research.

Is it worth today investigating the thought of the Chilean biologists? In my humble opinion - it is. Drifting among many of their ideas, expressed in difficult and hermeneutical-like language is challenging. I can certainly guarantee that the researcher-reader will be provided with a new perspective on the world of biology and interdisciplinary sciences. 


\section{References}

Boden M., 2000, Autopoiesis and life, Cognitive Science Quarterly 1: 117-145.

Boycott B. B., Lettvin J. Y., Maturana H. R. \& Wall P. D., 1965, Octopus Optic Responses, Experimental Neurology 12: 247-56.

Camus P. A., 2000, Evolution in Chile: natural drift versus natural selection, or the preservation of favoured theories in the struggle for knowledge, Revista Chilena de Historia Natural 73.

Detours V., Bersini H, Stewart J. \& Varela F. J., 1994, Development of an idiotypic network in shape space, Journal of Theoretical Biology 170: 401-14.

Dell P., 1985, Understanding Bateson and Maturana: Towards a biological foundation for the social sciences, Journal of Marital Family Therapy 11: 1-20.

Fleischaker G., 1988, Autopoiesis: the status of its system logic, BioSystems 22: 37-49.

Foerster H., 1973, On constructing a reality, [in] Observing Systems: 288-309.

Ganti T., 1975, Organization of chemical reactions into dividing and metabolizing units: the chemotons, BioSystems 7: 15-21.

Ganti T., 2003, The Principles of Life, Oxford University Press, Oxford.

Kauffman S., 1993, The Origins of Order: Self-Organization and Selection in Evolution, Oxford University Press, Oxford.

Kincaid D. L., 1987, The Convergence Theory of Communication, Self-Organization, and Cultural Evolution, [in:] D. L. Kincaid (ed.), Communication Theory: Eastern and Western Perspectives, Academic Press, San Diego, California.

Krippendorff K., 1987, Paradigms for Communication and Development with Emphasis on Autopoiesis, [in:] D. L. Kincaid (ed.), Communication Theory: Eastern and Western Perspectives, Academic Press, San Diego, California.

Lettvin J. Y., Maturana H., McCulloch W. S. \& Pitts, W. H., 1959, What the frog's eye tells the frog brain, Proceedings of The Institute of Radio Engineers 47(11): 233 258 .

Lewontin R. C., 1983a, The organism as the subject and object of evolution, Scientia 188: 65-82.

Lewontin R. C., 1983b, Biological determinism, Tanner Lectures on Human Values 4: 147-183.

Lewontin R. C., 1991, Biology as ideology: The doctrine of DNA, Harper Collins, New York.

Luhmann N., 1986, The autopoiesis of social systems, [in:] F. Geyer \& J. van der Zouwen, (eds.), Sociocybernetic Paradoxes, Sage, London.
Luhmann N., 1987, Closure and openness: On reality in the world of law, [in:] G. Teubner (ed.), Autopoiesis and the Law, de Gruyter, Berlin.

Luisi P. L., 2006, The Emergence of Life: From Chemical Origins to Synthetic Biology, Cambridge University Press.

Luisi P. L., 2002, Emergence in chemistry: chemistry as the embodiment of emergence, Foundations of Chemistry 4(3): 183-200.

Luisi P. L., Lazcano A. \& Varela F. J., 1996, What is life? Defining life and the transition to life, [in:] M. Rizzotti (ed.), Defining life: the central problem in theoretical biology, Edizione Universit di Padova, Padua.

Luisi P. L. \& Varela F. J., 1989, Self-replicating micelles: a chemical version of minimal autopoietic systems, Origins of Life and Evolution of Biospheres 19: 633643.

Maturana H. R., 1975, The organization of the living: A theory of the living organization, International Journal of Man-Machine Studies 7: 313-332.

Maturana H. R., 1985, The mind is not in the head, Journal of Structural Biology 8: 303-311.

Maturana H. R., 1990, Ontology of observing. The biological foundations of self consciousness and the physical domain of existence, [in:] N. Luhmann (ed.), Beobacheter: Konvergeng der Erkenntnistheorien? Wilhem Fink Verlag, München.

Maturana H. R. \& Mpodozis J., 2000, The origin of species by means of natural drift, Revista Chilena de Historia Natural 73.

Maturana H. R., Mpodozis J. \& Letelier J. C., 1995, Brain, language and the origin of human mental functions, Biological Research 28: 15-26.

Maturana H. R., Uribe G. \& Frenk S., 1968, A biological theory of relativistic colour coding in the primate retina, Archiva de Biologia y Medicina Experimentales, Suplemento 1: 1-30.

Maturana H. R. \& Varela F. J., 1987, The Tree of Knowledge: The Biological Roots of Human Understanding, Shambhala, Boston.

McMullin B. \& Varela F. J., 1997, Rediscovering computational autopoiesis. [in:] P. Husbands \& J. Harvey (eds.), Proceedings of the fourth European conference on artificial life, MIT Press, Cambridge, MA.

Mingers J., 1989, An introduction to autopoiesis - implications and applications, Systemic Practice and Action Research 2: 159-180.

Mingers J., 1990, The philosophical implications of Maturana's cognitive theories, Systemic Practice and Action Research 3: 569-584.

Mingers J., 1995, Self-Producing Systems - Implications and Applications of Autopoiesis, Plenum Press, New York. 
Oyama S., 2000, Evolution's eye: a systems view of the biology-culture divide, Duke University Press, Durham NC.

Rozzi R., Hargrove R., Armestro J. J., Picket S. \& Silander Jr. S., 1998, "Natural drift" as a post-modern evolutionary metaphor, Revista Chilena de Historia Natural 71: $5-17$.

Varela F. J., 1979, Principles of Biological Autonomy, Elsevier/North-Holland, New York.

Varela F. J., 1989, Reflections on the circulation of concepts between a biology of cognition and systemic family therapy, Family Procedure 28: 15-24.

Varela F. J., 1997, Patterns of life: intertwining identity and cognition, Brain \& Cognition, 34(1): 72-87.

Varela F. J. \& Bourgine P. (eds.), 1991, Toward a practice of autonomous systems, Proceedings of the First Eu- ropean Conference on Artificial Life, The MIT Press Cambridge, MA.

Varela F. J. \& Coutinho A., 1991, Second generation immune networks, Immunology Today, 12: 159-166.

Varela F. J. \& Maturana H. R., 1980, Autopoiesis and Cognition: The Realization of the Living, D. Reidel Publishing, Dordrecht: Holland/Boston USA.

Varela F. J., Maturana, H. R. \& Uribe R., 1974, Autopoiesis: The organization of living systems, its characterization and a model, Biosystems 5: 187-196.

Zeleny M., 1997, Self-Organization of Living Systems: A Formal Model of Autopoiesis, International Journal of General Systems 4: 13-28. 